\title{
Contact-Independent Antagonism of Ophidiomyces ophiodiicola, the Causative Agent of Snake Fungal Disease by Rhodococcus rhodochrous DAP 96253 and Select Volatile Organic Compounds
}

\author{
Christopher T Cornelison*, Blake Cherney, Kyle T Gabriel, Courtney K Barlament and Sidney A Crow Jr \\ Applied and Environmental Microbiology, Georgia State University, Atlanta, GA, USA
}

\begin{abstract}
Snake fungal disease (SFD), caused by the ascomycete Ophidiomyces ophiodiicola, has been associated with severe morbidity and mortality of numerous species of wild snakes in 15 US states. Accordingly, SFD was added to the horizon scan of global conservation issues in 2014. Due to the itinerant and secluded nature of many snake species, as well as the diversity of species impacted by SFD, estimating SFD-associated mortalities has been challenging. Regardless, the impacts have been shown to be significant in local and regional instances. Currently there is no known therapeutic or prophylactic for SFD. This study evaluated a potential biological treatment option for SFD that has shown promise in managing white-nose syndrome in bats, the bacterium $R$ hodococcus rhodochrous DAP 96253. R. rhodochrous was evaluated for in vitro contact-independent antagonism of $O$. ophiodiicola, with positive results. Additionally, synthetic volatile organic compounds (VOCs) associated with fungistatic soils were evaluated individually and in combinations to determine their potential for use as chemical control agents of SFD. In all cases an inhibitory effect was observed and statistically significant $(p<0.05)$ radial growth inhibition was observed in several cases. The results presented in this study provide initial evidence for the in vivo evaluation of the potential of these agents to prevent or reduce the morbidity and mortality associated with SFD.
\end{abstract}

Keywords: Rhodococcus; Ophidiomyces; Snakes; VOCs; Antagonism

\section{Introduction}

Beginning in 2006, an increasing number of snakes infected with a fungal dermatitis has been reported [1]. Cases have been confirmed in Florida, Georgia, Illinois, Massachusetts, Michigan, Minnesota, New Jersey, New York, Ohio, Tennessee, Wisconsin, and Virginia [1,2]. This disease is commonly known as snake fungal disease (SFD), and is attributed to Ophidiomyces ophiodiicola as the causative agent $[3,4]$. Most snakes develop symptoms of brittle scales, subcutaneous nodules, severe swelling in the periocular tissues, and premature shedding $[1,2,5,6]$. Most case studies on SFD with vipers have reported lesions around the facial region, which negatively influence the snake's ability to forage and survive in the wild $[1,2,5,6]$. The specific mechanism(s) of virulence and pathogenicity is currently unknown.

In 2014, SFD was declared in the horizon scan of global conservation issues due to the similar characteristics it shares with another fungal pathogen, Pseudogymnoascus destructans, the causative agent of whitenose syndrome (WNS) in bats [7]. The transmission route of SFD remains unknown, however, it is hypothesized to be environmentally transmitted due to the broad host range and annual cycle of infection $[1,2,5,6]$. Tracking the spread of this disease is very challenging due to the snake's varied habitat and secretive lifestyle, indicating that cases likely exists outside the currently known range of SFD.

Population declines of venomous and nonvenomous snake species is of significant ecological concern as many species (e.g., eastern indigo snake, Drymarchon couperi) are considered keystone species in their respective ecosystems. Snakes play the fundamental role of middle predator in the environment, which keeps small mammal populations, such as rodents, under control $[7,8]$. Rodents are known vectors of human pathogens, which the Centers for Disease Control (CDC) states can cause over 35 diseases capable of being spread to humans through direct or indirect contact via bodily fluids [9]. Healthy and stable populations of middle predators, such as snakes, limit rodent populations, which decreases the likelihood of diseases transmission to humans. Additionally, research on snake venom is now used as a form of natural product for antivenins, anticoagulants, treating hemophilia, and studying neural toxins, myotoxins and their structure and function $[10,11]$. Snakes also play an enormous role in the private pet trade, amounting to an estimated total expenditure of \$264 million a year in the US, making the US one of the largest exporters in this global industry [12].

With annually increasing reports of SFD, there is a growing concern for the health of snakes and the industries that rely on them, as well as the ecosystem services they provide. Clark et al. documented populations of the timber rattlesnake decreasing by 50 percent from 2006 to 2007 in New Hampshire [13]. Other states, such as Illinois, observed 100 percent mortality of massasauga rattlesnakes when infected with O. ophiodiicola [5]. Current antifungal treatments, such as ketoconazole and the surgical removal of an infected area, are often ineffective and lead to mortality $[2,6]$.

Recently, a naturally-occurring Gram-positive bacterium, Rhodococcus rhodochrous was evaluated as a potential biological control agent for SFD. Previous research with this bacteria has shown promising results for the management of pathogenic fungal infections caused by $P$. destructans, the fungus responsible for the recent decline in bat populations in North America [14]. Given the similarity of traits

*Corresponding author: Christopher T Cornelison, Senior Scientist, Applied and Environmental Microbiology, Georgia State University, $161 \mathrm{Dr}$. Jesse Hill Jr., Atlanta, Georgia 30303, United States of America, Tel: 4044135202; E-mail: ccornelison1@gsu.edu

Received October 18, 2016; Accepted October 25, 2016; Published October 31, 2016

Citation: Cornelison CT, Cherney B, Gabriel KT, Barlament CK, Crow Jr SA (2016) Contact-Independent Antagonism of Ophidiomyces ophiodiicola, the Causative Agent of Snake Fungal Disease by Rhodococcus rhodochrous DAP 96253 and Select Volatile Organic Compounds. J Vet Sci Technol 7: 397. doi: 10.4172/2157 7579.1000397

Copyright: (C) 2016 Cornelison CT, et al. This is an open-access article distributed under the terms of the Creative Commons Attribution License, which permits unrestricted use, distribution, and reproduction in any medium, provided the original author and source are credited. 
Citation: Cornelison CT, Cherney B, Gabriel KT, Barlament CK, Crow Jr SA (2016) Contact-Independent Antagonism of Ophidiomyces ophiodiicola, the Causative Agent of Snake Fungal Disease by Rhodococcus rhodochrous DAP 96253 and Select Volatile Organic Compounds. J Vet Sci Technol 7: 397. doi: 10.4172/2157-7579.1000397

Page 2 of 6

between SFD and WNS, it was hypothesized that $R$. rhodochrous could have similar effects on O. ophiodiicola.

R. rhodochrous has a long history in industrial applications [15]. This bacterium has been used extensively in bioremediation due to its diverse metabolic activity, including the ability to breakdown complex hydrophobic pollutants as well as the bacterium's presence in pristine and contaminated environments [15]. R. rhodochrous is also being evaluated for the ability to delay the ripening of climacteric fruits and vegetables to lengthen the shelf-life of human food stocks [16].

An additional line on inquiry in this study was evaluating the potential of naturally-occurring bacterially-produced volatile organic compounds (VOCs), associated with fungistatic soils, to inhibit the growth of $O$. ophiodiicola in vitro. Fungistatic soils occur globally and their antifungal activities are attributed to the generation of antagonistic VOCs by microbial community members [17-23]. Synthetically-produced VOCs were selected and introduced into a shared airspace with mycelia plugs to evaluate the antifungal activity of select VOCs. The compounds that were selected for this study were $\mathrm{N}$, $\mathrm{N}$ dimethyloctylamine, benzothiazole, benzaldehyde, 2-phenylethanol, 2-ethyl-1-hexanol, propionic acid, 2-nonanone, decanal, styrene, and nonanal [17,19,21-23]. All compounds were introduced to fungal plug assays at $4 \mu \mathrm{mols}$. The five least toxic (based on LD50 with rats, S1) and the five most inhibitive (Table 1) were selected for combination trials of two and three VOCS to determine whether or not they have synergistic activities at equimolar ratios. Most fungistatic VOCs are produced by soil-dwelling bacteria $[17,20]$. There have been extensive studies conducted on fungistatic activity and the microbes that are correlated to the particular VOCs released into the soil [17-23]. Surveys of soil bacteria have reported that $30-60 \%$ of isolated microbiota produce VOCs that can inhibit fungi [20], indicative of the vast number of candidates not screened in this study and the potential of mining these communities for control agents for emerging fungal pathogens.

Current research showing induced cells of $R$. rhodochrous strain DAP 96253 and bacterially-produced VOCs as a possible treatment for WNS, establishes a precedent for this approach in the control of other emerging wildlife mycoses [14,18]. Initial in vitro evaluations of this approach in the management of SFD has been favourable and is presented below.

\section{Materials and Methods}

\section{Culture acquisition and maintenance}

Isolates of O. ophiodiicola (isolate number 10-1197) were obtained

\begin{tabular}{|c|c|}
\hline Voc & $\begin{array}{c}\text { Total area of mycelia }\left(\mathbf{m m}^{\mathbf{2}}\right) \mathbf{7} \text { days post } \\
\text { inoculation }\end{array}$ \\
\hline Nonanal & 150.61 \\
\hline 2-Ethyl-1-hexanol & 204.13 \\
\hline Benzaldehyde & 345.13 \\
\hline Propionic acid & 365.23 \\
\hline N,N-Dimethyloctylamine & 373.87 \\
\hline Decanal & 378.95 \\
\hline 2-Phenylethanol & 418.93 \\
\hline Benzothiazole & 638.96 \\
\hline 2-Nonanone & 650.02 \\
\hline Styrene & 753.60 \\
\hline Control & 681.85 \\
\hline
\end{tabular}

Table 1: Averaged radial growth of single VOC exposures and control (most to least inhibitive). Each trial was performed in triplicate and the average of all exposures is represented below. from the University of California Davis, School of Veterinary Medicine Department of Pathology, Microbiology \& Immunology. Cultures were lawn streaked and grown on Sabouraud Dextrose Agar (SDA, Difco) then incubated for 7 to 10 days at $30^{\circ} \mathrm{C}$ or until the entire agar surface was covered with mycelial growth. Conidia of $O$. ophiodiicola were harvested according to the methods of Cornelison et al. [18]. For storage, the conidia solution was centrifuged at 3,000 rpm and the supernatant was removed. $10 \mathrm{ml}$ of $25 \%$ glycerol solution was added to the resulting pellet and this mixture was vortexed. The conidia concentration was determined via hemocytometer (Bright-Line, Pennsylvania). Conidia solutions were stored at $-80^{\circ} \mathrm{C}$ until use. All $R$. rhodochrous glycerol stock aliquots were prepared according to the methods of Pierce et al. [16,24,25]. Fresh glycerol stocks were used as the source of cells at the onset of each assay. The induction process was performed using the addition of either urea or urea and cobalt as described by Pierce et al. [16,24,25].

\section{Co-culture assays with $R$. rhodochrous}

Co-culture assays were carried out according to the methods of Cornelison et al. [14] and modified as follows. A Petri plate $(60 \mathrm{~mm} \times$ $15 \mathrm{~mm}$ ) containing SDA was inoculated with $50 \mu \mathrm{l}$ of O. ophiodiicola conidia solution $\left(1.4 \times 10^{6}\right.$ conidia $\left.\mathrm{ml}^{-1}\right)$ and placed in a shared airspace (150 mm $\times 15 \mathrm{~mm}$ ) with cells of $R$. rhodochrous (treatment) or alone (control) and sealed with Parafilm M (Sigma-Aldrich, Missouri). All experimental setups remained sealed for 8 days or until the controls had formed a congruent mycelial lawn on the SDA $(60 \mathrm{~mm} \times 15$ $\mathrm{mm})$. All assays were performed in triplicate. In order to identify if $R$. rhodochrous has the ability to inhibit vegetative hyphae growth of O. ophiodiicola, mycelial plug assays were used to quantify the radial growth of O. ophiodiicola. A lawn of O. ophiodiicola was grown from conidia for 7-10 days and a $5 \mathrm{~mm}$ diameter transfer tube (Spectrum Medical, SC) was used to extract full depth mycelial plugs from the lawn of O. ophiodiicola. Each plug was then inserted into a fresh plate of SDA $(60 \mathrm{~mm} \times 15 \mathrm{~mm})$. The resulting mycelial plug plates were placed into a shared airspace $(150 \mathrm{~mm} \times 15 \mathrm{~mm})$ alone (control) or with two plates $(60 \mathrm{~mm} \times 15 \mathrm{~mm})$ of induced $R$. rhodochrous (treatment) and sealed with Parafilm M.

\section{Induced $R$. rhodochrous germule suppression assay}

Germule suppression assays were conducted according to the methods of Cornelison et al. [14] and modified as follows. Slide agar overlays were inoculated with $50 \mu \mathrm{l}$ of conidia suspension $\left(1.4 \times 10^{6}\right.$ conidia $\mathrm{ml}^{-1}$ ). Plates of induced $R$. rhodochrous were removed after 24 and 48 hours of exposure. Slide agars were then observed at 21 days post inoculation. Microscopic observation of slide agar overlays utilized a Nikon Eclipse model E600 (Japan) in Differential Interference Contrast (DIC). The camera used to capture photos was a Nikon D7000. A germule is defined as a mycelial extension from a single conidia greater than the length of the intact conidia.

\section{Preparation of fermentation cell-paste in non-growth conditions}

The preparation of fermentation cell paste was produced according to the methods of Pierce et al. [16,24,25]. Fermentation cell paste is a high cell density aggregate from $30 \mathrm{~L}$ fermentations of $R$. rhodochrous DAP96253 that has been centrifuged to remove spent media. The assessment of anti-fungal activity of $O$. ophiodiicola was observed by mycelial plugs assays, with 1 and 2 grams of fermentation paste per shared airspace in treatment samples and no cell paste in controls. 
Citation: Cornelison CT, Cherney B, Gabriel KT, Barlament CK, Crow Jr SA (2016) Contact-Independent Antagonism of Ophidiomyces ophiodiicola, the Causative Agent of Snake Fungal Disease by Rhodococcus rhodochrous DAP 96253 and Select Volatile Organic Compounds. J Vet Sci Technol 7: 397. doi: 10.4172/2157-7579.1000397

Page 3 of 6

\section{VOC combination assay for anti-O. ophiodiicola activity}

VOCs were tested individually in exposure assays to determine if specific compounds were antifungal against $O$. ophiodiicola. Previous research has shown numerous naturally-occurring VOCs to have antifungal activity. The following compounds were selected for VOC exposure assays in this study: N,N-dimethyloctylamine, benzothiazole, benzaldehyde, 2-phenylethanol, 2-ethyl-1-hexanol, propionic acid, 2-nonanone, decanal, styrene, and nonanal [17,19,21-23]. All VOCs were procured as pure liquid research-grade chemical reagents (SigmaAldrich, Missouri) without any modification for exposure assays. Single VOC exposures were performed at a quantity of $4.0 \mu \mathrm{mol}$ on each absorbent disc in a closed air space $(150 \mathrm{~mm} \times 15 \mathrm{~mm})$. Fungal plugs from a fresh mycelial lawn were inserted into a SDA Petri plate $(60 \mathrm{~mm} \times 15 \mathrm{~mm})$ and placed in the closed airspace with the specific VOC disc. All assays were sealed with Parafilm $\mathrm{M}$ and incubated for 7 days at $30^{\circ} \mathrm{C}$. Plugs were photographed every 24 hours in order to measure radial mycelial expansion. Each VOC was ranked according to the level inhibition of $O$. ophiodiicola in single-dose exposures performed in triplicate and averaged. Compounds were also ranked based on toxicity, according to median lethal dose (LD50) reported in the literature (S1). From those rankings, five VOCs were selected and paired in all different combinations with $2 \mu$ mols of each compound ( $4 \mu \mathrm{mol}$ total) in a closed airspace. Similarly, the same 5 compounds were combined in combinations of 3 with $1.3 \mu$ mols of each compound in a closed airspace. $\mathrm{N}, \mathrm{N}$-dimethyloctylamine was excluded from the combination trials because of its high toxicity (S1) and replaced with the next most inhibitory compound, decanal (47.6\%). The goal was to select the most effective compounds with the lowest reported toxicity (S1). All trials were performed in triplicate and radial mycelial growth was quantified over 7 days and averaged.

\section{Area measurement of radial growth with digital photography and open-source software}

The area of radial mycelial growth was determined using the open-source photo editing software package GIMP (GNU Image Manipulation Program). Area quantification of mycelia plugs were obtained according to the methods of Cornelison et al. [18]

\section{Results}

\section{Co-culture assays with $R$. rhodochrous}

Plates of induced cells of $R$. rhodochrous were placed in a closed airspace along with conidia-inoculated SDA Petri plates of $O$. ophiodiicola. 7 days post-inoculation, the Petri plates in a shared airspace with $R$. rhodochrous had no visible growth (Figure 1a) whereas the controls had formed a congruent lawn over the entire agar surface (Figure 1b).

In the radial mycelial extension assays using vegetative mycelial plugs, $R$. rhodochrous produced statistically significant radial growth inhibition in days 3-6 post-inoculation ( $\mathrm{p}<0.05$, Figure 2$)$. Radial area measurements on days 3, 5 and 6 showed a percent inhibition greater than $100 \%$, due to the inhibited treatment plugs shrinking due to desiccation. Although the fungal plugs did show radial expansion in the first 24 hours post-inoculation, radial expansion was significantly inhibited in subsequent days (Figure 2).

\section{Induced $R$. rhodochrous germule suppression assay}

O. ophiodiicola conidia on slide agar overlays were exposed to cells of induced $R$. rhodochrous on media in a closed airspace at $30^{\circ} \mathrm{C}$ for 24 and 48 hours (Figures 3b-3d). After removal of R. rhodochrous from the shared airspace the slides were monitored for 21 days to determine if the exposed conidia were capable of generating germules. These exposed slides were compared to the unexposed control slides inoculated with O. ophiodiicola conidia, which had over-grown the slide agar overlays after 8 days (Figure 3a). No germules were identified on slides exposed to $R$. rhodochrous whereas control slides showed significant mycelial growth and sporulation. These results validate the hypothesis that $R$. rhodochrous can inhibit germination of $O$. ophiodiicola with as little as 24 hours of exposure (Figure $3 b$ ).

\section{Anti-O. ophiodiicola activity of fermentation cell-paste}

Non-growth cell-paste trials were conducted with 24 hour postharvest cell-paste (fresh), and 44 day-old cell-paste stored at $4^{\circ} \mathrm{C}$ (stored), to evaluate the influence of cold storage on the antifungal activity of $R$. rhodochrous fermentation cell-paste. Both fresh and stored cell-paste demonstrated inhibitory activity against O. ophiodiicola (Figure 4), although fresh cell-paste was quantitatively more inhibitory.

\section{Single VOC trials}

O. ophiodiicola mycelial plugs were exposed to $4 \mu \mathrm{mol}$ of ten different VOCs individually. The five most inhibitory VOCs were nonanal, 2-ethyl-1-hexanol, benzaldehyde, propionic acid, and $\mathrm{N}$, $\mathrm{N}$-dimethyloctylamine with averaged $(\mathrm{n}=3)$ percent inhibitions after 7 days of $80.6 \%, 80.5 \%, 52.9 \%, 59.0 \%$, and $53.4 \%$ respectively (Figure 5).

\section{Combinations of 2 VOCs}

Overall combinations of 2 VOCs inhibited growth to a greater extent compared to the single VOC trials, supporting the hypothesis that select VOCs can work synergistically. The most effective combination was 2-ethyl-1-hexanol, and nonanal yielding an average of $94 \%$ inhibition over a period of 7 days (Figure 6). The second highest percent inhibition resulted from an equimolar combination of benzaldehyde, and 2-ethyl-1-hexanol, yielding an average of $93 \%$ inhibition over a period of 7 days (Figure 6).

\section{Combinations of 3 VOCs}

All combinations of VOCs were more effective at inhibiting radial mycelial extension of $O$. ophiodiicola compared to any VOC alone at equivalent moles (Figure 7). The two combinations of 3 VOCs that had the highest percent inhibition were benzaldehyde, propionic acid, and nonanal yielding an average of $88 \%$ inhibition over a period of 7 days, and nonanal, 2-ethyl-1-hexanol, and propionic acid yielding an average of $85.1 \%$ inhibition of radial growth compared to controls (Figure 7).

\section{Discussion}

Emerging fungal pathogens are threatening wildlife around the globe and have been reported to be increasing in incidence and severity over the past several decades [26]. Fungal pathogens present numerous challenges to disease management and microbial control efforts. This is primarily due to the ability of these fungi to thrive in host-free environmental reservoirs as well as their taxonomic similarity to their hosts (i.e., Eukarya/Eukarya). Consequently, antifungal agents used to treat human mycoses may have toxic effects on susceptible animals or be cost-prohibitive for large scale wildlife applications. Accordingly, the identification and evaluation of novel approaches to managing fungal pathogens of wildlife are needed to avert these potential ecological disasters.

Cases of SFD have increased significantly since 2006 [1]. Currently, 
Citation: Cornelison CT, Cherney B, Gabriel KT, Barlament CK, Crow Jr SA (2016) Contact-Independent Antagonism of Ophidiomyces ophiodiicola, the Causative Agent of Snake Fungal Disease by Rhodococcus rhodochrous DAP 96253 and Select Volatile Organic Compounds. J Vet Sci Technol 7: 397. doi: 10.4172/2157-7579.1000397
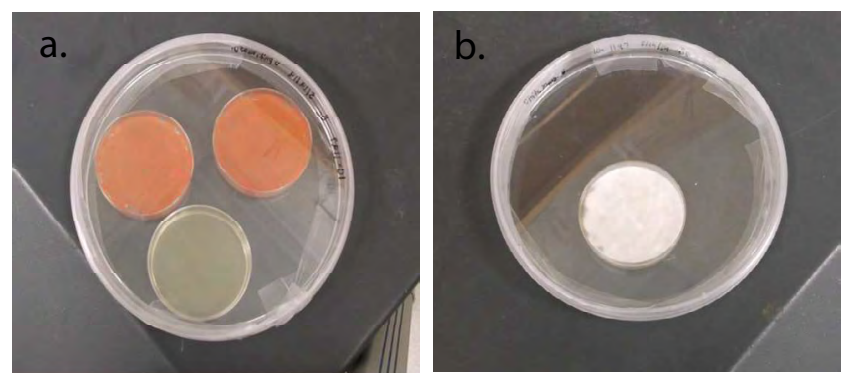

Figure 1: Co-culture assays with $R$. rhodochrous. 7 days post inoculation with $50 \mu \mathrm{l}$ of $10^{8} \mathrm{O}$. ophiodiicola conidia $\mathrm{ml}^{-1}$ in a closed airspace with induced $R$. rhodochrous (a) as well as in the absence of $R$. rhodochrous (b).

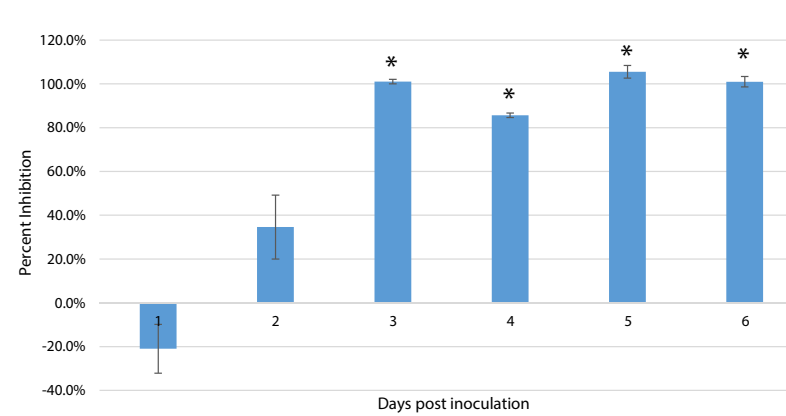

Figure 2: Average percent inhibition of $O$. ophiodiicola radial expansion in a shared airspace with $R$. rhodochrous. "indicates statistically significant $(p<0.05)$ inhibition compared to unexposed controls.

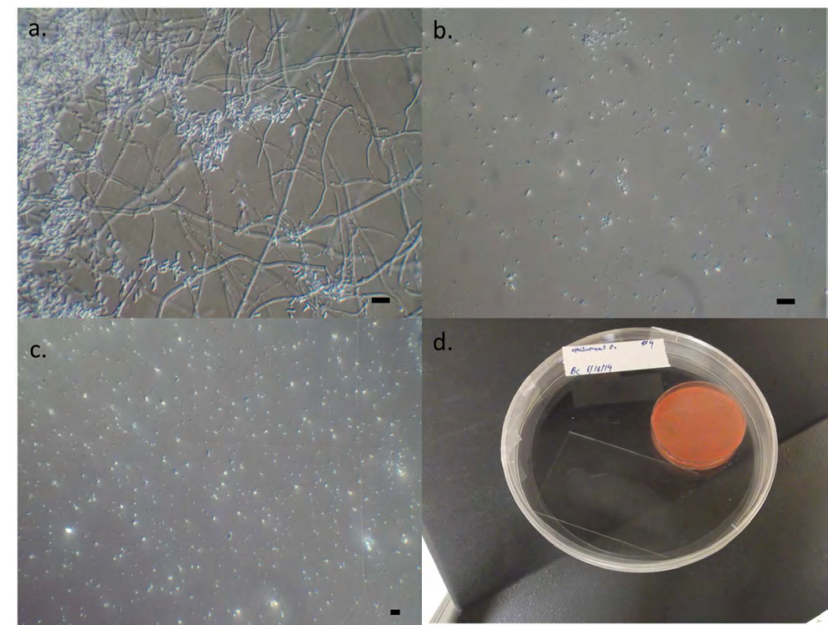

Figure 3: Germule suppression assay. $50 \mu \mathrm{l}$ of $10^{6} \mathrm{O}$. ophiodiicola conidia $\mathrm{ml}^{-1}$ were inoculated on slide agars overlays and stored at $30^{\circ} \mathrm{C}$. Images were captured 8 days post inoculation. The control exhibits normal growth characteristics. (a) $24 \mathrm{hr}$. exposure of $R$. rhodochrous inhibits germination and germules are unable to recover after exposure. (b) $48 \mathrm{hr}$. exposure to $R$. rhodochrous inhibits germination. (c) Experimental setup (d) Images a and $\mathrm{b}$ are captured at $400 \mathrm{X}$ and $\mathrm{c}$ is captured at 200X. Scale bars are $10 \mu \mathrm{m}$.

SFD is confirmed in 15 states and continues to spread [1,2]. Disease management options for this mycosis are currently lacking, yet they may be vital to preventing regional extirpation of imperilled species such as the Eastern Massasauga Rattlesnake. The results presented in this study suggest that both $R$. rhodochrous and fungistatic soil-associated
VOCs may have utility in managing SFD, and warrant additional, in vivo, evaluation $[27,28]$. Specifically, evaluating the potential of these agents to address the deep tissue granulomas characteristic of advanced SFD will be critical for establishing these agents as clinical tools in the treatment of SFD [29].

Rhodococcus rhodochrous, a naturally-occurring soil bacterium, can irreversibly inhibit spore germination (Figure 3 ) and significantly inhibit radial mycelial elongation (Figure 2). Complete inhibition of conidia is beneficial for disease management purposes because it prevents any remnant conidia from germinating and growing after the treatment is complete. Additionally, as with many fungal pathogens, spores are likely the primary transmittable disease agent. Rendering these spores nonviable may reduce the spread of SFD in addition to potentially ameliorating the effects of SFD on individual hosts [30,31].

The ability to produce induced $R$. rhodochrous in large-scale fermentations, store at $4^{\circ} \mathrm{C}$, and retain antifungal activity establishes the logistical feasibility of this organisms for disease management applications. Additionally, the well-established utility and safety of this organism for diverse industrial applications is supportive of the benign nature of large-scale applications and environmental release, although the evaluation of the potential for non-target effects will need to be conducted to ensure safety prior to any in situ applications being considered [32,33].

Mycelial plug assays using VOCs have also produced favourable results. Individual VOCs produced significant inhibition, but even greater inhibition was observed when VOCs were used in equimolar combinations, with select combinations demonstrating significant synergistic activities. In addition, snakes are not a traditional model for toxicity assessments; therefore, the toxicity, as LD50 with rats, was used only as general estimate for ranking individual VOC toxicity. Using a low dosage of less toxic compounds can be used as a way to achieve impactful efficacy in fungal control and limit the potential toxicity associated with antifungal agents [34]. The efficacy of antifungal VOCs for in situ application in the control of SFD is currently unknown. There are several key factors which play a role in natural examples of fungistasis that will also influence field performance in managing SFD (for example, physical barriers to diffusion, humidity, airflow and temperature). These factors will vary from site to site and must be considered when evaluating to the potential of VOCs for in situ applications.

As the incidence and prevalence of emerging fungal pathogens expands, novel tools must be developed to facilitate active management of these pathogens. Fungal pathogens, such as O. ophiodiicola, are capable of surviving and potentially amplifying in host-free environments requiring environmental mitigations to reduce disease incidence within a population. In these cases, agents capable of rendering conidia non-viable may have significant utility and should be the focus of efforts to develop mitigation plans for SFD in atrisk populations. However, in vitro activity, such as reported in this manuscript, does not serve as an ideal predictor of efficacy in the field. While in situ disease management for wild snakes will be the ultimate goal for managing SFD, developing disease mitigation tools for application in the natural environment presents numerous challenges and necessitates further investigation. The initial findings presented in this manuscript justify further in vivo evaluation of $R$. rhodochrous and select VOCs for the clinical management of SFD in captive recovery programs and in captive collections (e.g., zoos, pet trade) $[35,36]$. 
Citation: Cornelison CT, Cherney B, Gabriel KT, Barlament CK, Crow Jr SA (2016) Contact-Independent Antagonism of Ophidiomyces ophiodiicola, the Causative Agent of Snake Fungal Disease by Rhodococcus rhodochrous DAP 96253 and Select Volatile Organic Compounds. J Vet Sci Technol 7: 397. doi: 10.4172/2157-7579.1000397

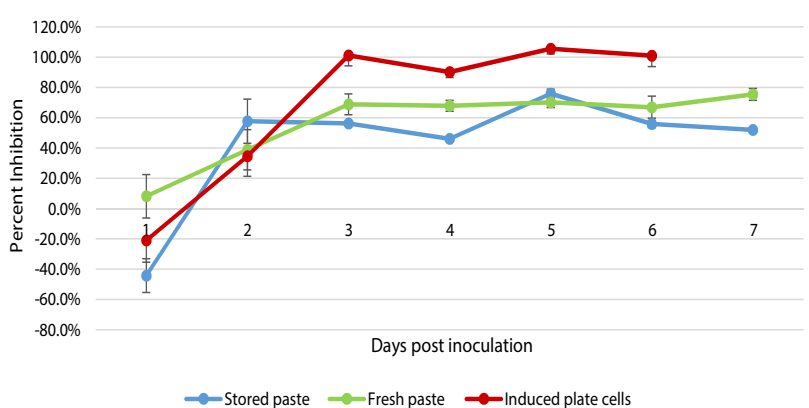

Figure 4: Biomass composition, age and media support influence efficacy against $O$. ophiodiicola. Percent inhibition of stored paste $\left(44\right.$ days at $\left.4^{\circ} \mathrm{C}\right)$, fresh paste ( $<24$ hours after harvesting from fermentation vessel) and induced plate cells (used while on induction agar). Percent inhibition was determined by comparing growth to unexposed controls, and averaged from triplicate.

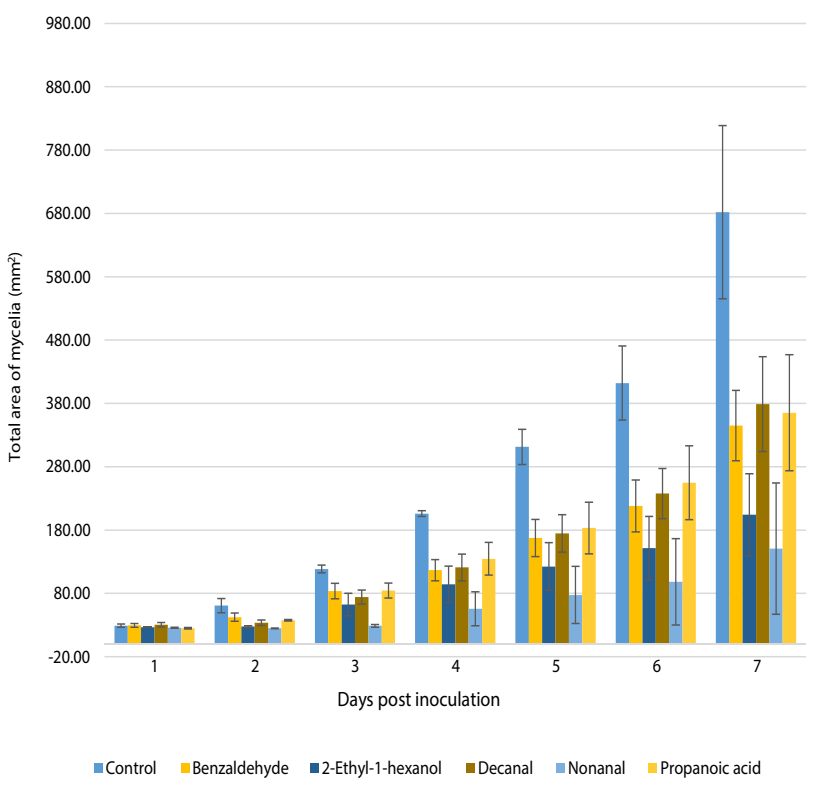

Figure 5: Radial growth of O. ophiodiicola with select VOCs.

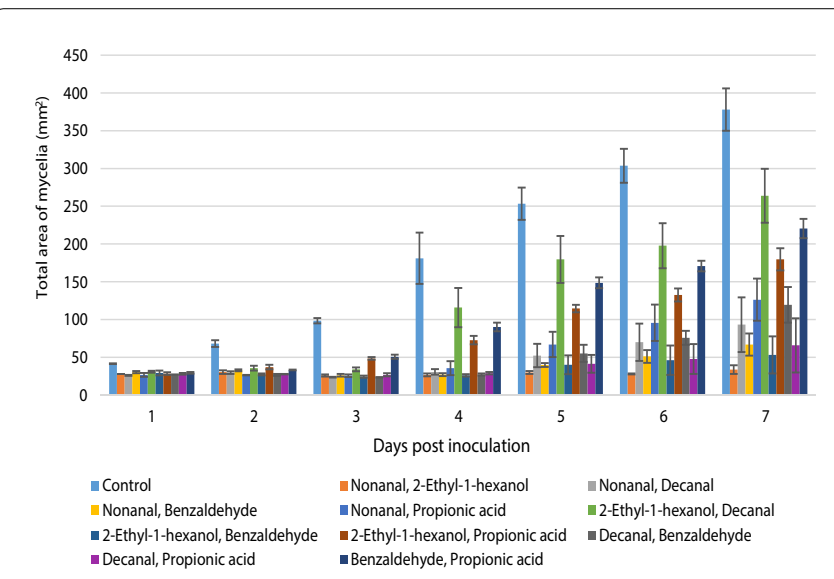

Figure 6: Radial growth of O. ophiodiicola with equimolar combinations of 2 VOCs.

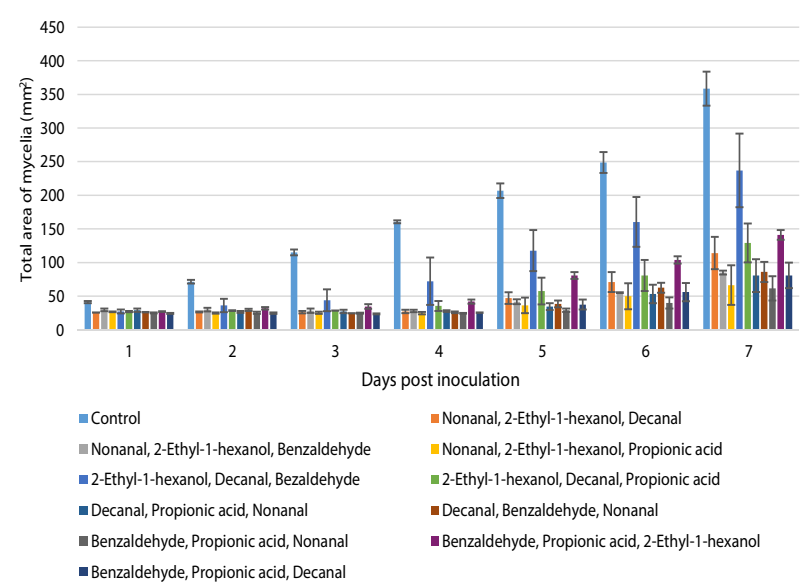

Figure 7: Radial growth of O. ophiodiicola with equimolar combinations of 3VOCs.

\section{Acknowledgments}

This work was supported by the Environmental Research Center at Georgia State University as well as the Georgia State University Research Foundation.

\section{Author Contributions}

CTC, KTG, and SAC conceived and designed the experiments; BC performed the experiments; CTC, BC, and SAC analyzed the data; CKB and KTG contributed reagents/materials/analysis tools; CTC and BC wrote the paper.

\section{Conflicts of Interest}

SAC is an inventor on the seminal patents on Rhodococcus rhodoochrous DAP 96253 induction and application. CTC and KTG are the inventors on a patent submission regarding VOC formulations for treating fungal disease. All issued and submitted patents relating to this work are held by the Georgia State University Research Foundation.

\section{References}

1. Sleeman J (2013) Snake fungal disease in the United States. National Wildlife Health Center Wildlife Health Bulletin 2: 1-3.

2. Allender MC, Raudabaugh DB, Gleason FH, Miller AN (2015) The natural history, ecology, and epidemiology of Ophidiomyces ophiodiicola and its potential impact on free-ranging snake populations. Fungal Ecology 17: 187196.

3. Allender MC, Baker S, Wylie D, Loper D, Dreslik MJ, et al. (2015) Development of snake fungal disease after experimental challenge with Ophidiomyces ophiodiicola in cottonmouths (Agkistrodon piscivorous). PLoS One 10: e0140193.

4. Lorch JM, Lankton J, Werner K, Falendysz EA, McCurley K, et al. (2015) Experimental infection of snakes with Ophidiomyces ophiodiicola causes pathological changes that typify snake fungal disease. mBio 6: e01534-15.

5. Allender MC, Dreslik M, Wylie S, Phillips C, Wylie DB, et al. (2011) Chrysosporium sp. infection in eastern massasauga rattlesnakes. Emerg Infect Dis 17: 2383-2385.

6. Rajeev S, Sutton DA, Wickes BL, Miller DL, Giri D, et al. (2009) Isolation and characterization of a new fungal species, Chrysosporium ophiodiicola, from a mycotic granuloma of a black rat snake (Elaphe obsoleta obsoleta). J Clin Microbiol 47: 1264-1268.

7. Sutherland WJ, Aveling R, Brooks TM, Clout M, Dicks LV, et al. (2014) A horizon scan of global conservation issues for 2014. Trends Ecol Evol 29: 1522.

8. Linzey DW, Clifford MJ (2002) Snakes of Virginia. 1st edn. University Press of Virginia, Charlottesville, USA.

9. Center of Disease Control and Prevention (2010) Rodents.

10. Hahn G (2009) Target Animal Safety for Veterinary Pharmaceutical Products 
Citation: Cornelison CT, Cherney B, Gabriel KT, Barlament CK, Crow Jr SA (2016) Contact-Independent Antagonism of Ophidiomyces ophiodiicola, the Causative Agent of Snake Fungal Disease by Rhodococcus rhodochrous DAP 96253 and Select Volatile Organic Compounds. J Vet Sci Technol 7: 397. doi: 10.4172/2157-7579.1000397

(VICH GL 43). In Berichte zu Tierarzneimitteln, Birkhäuser Basel, pp: 58-69.

11. Koh DCl, Armugam A, Jeyaseelan K (2006) Snake venom components and their applications in biomedicine. Cell Mol Life Sci CMLS 63: 3030-3041.

12. Collis AH, Fenili RN (2011) The Modern US Reptile Industry. Economic Analysis Group.

13. Clark RW, Marchand MN, Clifford BJ, Stechert R, Stephens S (2011) Decline of an isolated timber rattlesnake (Crotalus horridus) population: interactions between climate change, disease, and loss of genetic diversity. Biological Conservation 144: 886-891.

14. Cornelison CT, Keel MK, Gabriel KT, Barlament CK, Tucker TA, et al. (2014) A preliminary report on the contact-independent antagonism of Pseudogymnoascus destructans by Rhodococcus rhodochrous strain DAP96253. BMC Microbiol 14: 246.

15. Bell KS, Philp JC, Aw DWJ, Christofi N (1998) The genus Rhodococcus. J App Microbiol 85: 195-210.

16. Pierce GE, Drago GK, Ganguly S, Tucker TA, Hooker JW, Jones S, et al. (2011) Preliminary report on a catalyst derived from induced cells of Rhodococcus rhodochrous strain DAP 96253 that delays the ripening of selected climacteric fruit: bananas, avocados, and peaches. J Ind Microbiol Biotechnol 38: 15671573.

17. Chuankun X, Minghe M, Leming Z, Keqin Z (2004) Soil volatile fungistasis and volatile fungistatic compounds. Soil Biol Biochem 36: 1997-2004.

18. Cornelison CT, Gabriel KT, Barlament C, Crow Jr. SA (2014) Inhibition of Pseudogymnoascus destructans growth from conidia and mycelial extension by bacterially produced volatile organic compounds. Mycopathologia 177: 1-10.

19. Fernando WD, Ramarathnam R, Krishnamoorthy AS, Savchuk SC (2005) Identification and use of potential bacterial organic antifungal volatiles in biocontrol. Soil Biol Biochem 37: 955-964.

20. Garbeva P, Hol WG, Termorshuizen AJ, Kowalchuk GA, De Boer W (2011) Fungistasis and general soil biostasis-a new synthesis. Soil Biol Biochem 43: 469-477.

21. Liu W, Mu W, Zhu B, Liu F (2008) Antifungal activities and components of VOCs produced by Bacillus subtilis G8. Curr Res Bacteriol 1: 28-34.

22. Strobel GA, Kluck K, Hess WM, Sears J, Ezra D, et al. (2007) Muscodor albus $\mathrm{E}-6$, an endophyte of Guazuma ulmifolia making volatile antibiotics: isolation, characterization and experimental establishment in the host plant. Microbiol 153: 2613-2620.
23. Yuan J, Raza W, Shen Q, Huang Q (2012) Antifungal activity of Bacillus amyloliquefaciens NJN-6 volatile compounds against Fusarium oxysporum $\mathrm{f}$ sp. cubense. Appl Environ Microbiol 78: 5942-5944.

24. Pierce GE, Drago G, Ganguly S (2009) Induction and stabilization of enzymatic activity in microorganisms. US 7531343 B2

25. Pierce GE, Drago G, Ganguly S (2009) Induction and stabilization of enzymatic activity in microorganisms. US $7531344 \mathrm{~B} 2$.

26. Fisher MC, Henk DA, Briggs CJ, Brownstein JS, Madoff LC, et al. (2012) Emerging fungal threats to animal, plant and ecosystem health. Nature 484 186-194.

27. Chem ID plus. Octyldimethylamine. ChemIDplus Datatbank Number 7378-996. National Library of Medicine Bethesda (MD), USA.

28. Chem ID plus. 2-Nonanone. ChemIDplus Datatbank Number 821-55-6. National Library of Medicine Bethesda (MD), USA.

29. Hazardous Substances Data Bank (2015) 2-Ethyl-1-Hexanol. Hazard Hazardous Substances Databank Number: 1118. National Library of Medicine Bethesda (MD), USA.

30. Hazardous Substances Data Bank (2015) Nonanal. Hazard Hazardous Substances Databank Number: 7229. National Library of Medicine, Bethesda (MD), USA.

31. Hazardous Substances Data Bank (2015) Propionic Acid. Hazard Hazardous Substances Databank Number: 1192. National Library of Medicine, Bethesda (MD), USA.

32. Hazardous Substances Data Bank (2015) 1-Decanol. Hazard Hazardous Substances Databank Number: 1072. National Library of Medicine, Bethesda (MD), USA.

33. Hazardous Substances Data Bank (2005) Benzaldehyde. Hazard Hazardous Substances Databank Number: 388. National Library of Medicine, Bethesda (MD), USA.

34. Hazardous Substances Data Bank (2002) 2-Phenylethanol. Hazard Hazardous Substances Databank Number: 5002. National Library of Medicine, Bethesda (MD), USA.

35. Hazardous Substances Data Bank (2014) Styrene. Hazard Hazardous Substances Databank Number: 171. National Library of Medicine, Bethesda (MD), USA.

36. Reddy G, Mayhew DA (1992) Acute oral toxicity (LD50) study in rats with benzothiazole. Int J Toxicol 11: 666-666. 